\title{
Interações Medicamentosas entre Antibióticos e Anticoncepcionais, presentes em Prescrições Médicas
}

\author{
Deborah Soraia Brandão Mendonça ${ }^{1}$; Rafael Luiz Araújo Rodrigues ${ }^{2}$
}

\begin{abstract}
Resumo: O estudo trata sobre a ocorrência de interações medicamentosas entre antibióticos e anticoncepcionais numa farmácia de Vitória da Conquista. Conhecidos como pílulas anticoncepcionais, os contraceptivos são utilizados pela maioria da população feminina. Quando administradas junto com antimicrobianos, os contraceptivos podem não fazer efeito, deixando-as desprotegidas contra uma possível gravidez. Antibióticos são compostos naturais ou sintéticos capazes de inibir o crescimento ou causar a morte bactérias. Podem ser classificados como bactericidas, quando causam a morte da bactéria, ou bacteriostáticos, quando promovem a inibição do crescimento microbiano. Portanto este trabalho tem como objetivo a verificação do perfil da utilização e o reconhecimento das possíveis interações medicamentosas entre os antibióticos e anticoncepcionais. A metodologia trata-se de um estudo de levantamento de natureza qualitativa que tem como intervenção o esclarecimento ao paciente sobre as prescrições apresentadas no ambiente de uma farmácia.
\end{abstract}

Palavras Chave: Interações Medicamentosas. Antibióticos. Anticoncepcionais.

\section{Drug Interactions Between Antibiotics And Contraceptives Present in Medical Prescriptions}

\begin{abstract}
The study deals with the occurrence of drug interactions between antibiotics and contraceptives in a pharmacy in Vitória da Conquista. Known as birth control pills, contraceptives are used by the majority of the female population. When given along with antimicrobials, contraceptives may not work, leaving them unprotected against a possible pregnancy. Antibiotics are natural or synthetic compounds capable of inhibiting the growth or causing the death of bacteria. They can be classified as bactericidal, when they cause the death of the bacterium, or bacteriostatic, when they promote the inhibition of microbial growth. Therefore, this study aims to verify the profile of the use and the recognition of possible drug interactions between antibiotics and contraceptives. The methodology is a study of a qualitative survey that has as an intervention the clarification to the patient about the prescriptions presented in the environment of a pharmacy.
\end{abstract}

Keywords: Drug interactions. Antibiotics. Contraceptives

\section{Introdução}

Compreende-se por Interações Medicamentosas, as alterações nos efeitos farmacológicos esperados em decorrência de modificações em sua farmacocinética e/ou farmacodinâmica.

\footnotetext{
${ }^{1}$ Graduanda em Farmácia pela Faculdade Independente do Nordeste-FAINOR, Vitória da Conquista-Bahia. Email: deborahhfarmacia@gmail.com

${ }^{2}$ Professor Orientador da Faculdade Independente do Nordeste-FAINOR, Vitória da Conquista-Bahia. Email: faelfarmac@ hotmail.com
} 
O consumo de alimentos ou fatores intrínsecos relacionados ao paciente (idade, obesidade, patologias, etc), bem como a ingestão concomitante de outro medicamento representam possíveis causas dessas modificações (BEATRIZ; SOUZA, 2014). Embora em alguns casos, os resultados dessas combinações sejam benéficos, comumente as interações medicamentosas são indesejáveis e prejudiciais ao indivíduo (HANSTEN, 1989).

"Partindo-se da problemática interação medicamentosas, sabe-se que o uso concomitante de antimicrobianos e contraceptivos orais pode resultar em perda de eficácia contraceptiva e, consequentemente, uma gravidez inesperada." (NICOLINI, et al., 2008). Alguns mecanismos expressam a possibilidade de diminuição da eficácia do anticoncepcional com o uso de alguns antibióticos, que incluem diminuição da circulação entero-hepática pela redução na microbiota intestinal, responsável pela manutenção dos níveis plasmáticos constantes do contraceptivo oral e o aumento da sua degradação enzimática no fígado (MEIRELLES; ROCHA, 2013).

Os contraceptivos orais são formados por hormônio estrogênio e progesterona, que atuam na inibição da ovulação, atrofiando o revestimento do útero e dificultando a passagem dos espermatozóides devido ao aumento da viscosidade do muco cervical. Para diminuir os riscos cardiovasculares e outros efeitos colaterais associados às pílulas, as dosagens hormonais desses remédios foram reduzidas. "Sob circunstâncias normais, estas concentrações mais baixas são bastante efetivas. Assim como, na presença de antimicrobianos, os níveis hormonais, já reduzidos, podem cair ainda mais, comprometendo a eficácia dos contraceptivos orais" (BEATRIZ; SOUZA, 2014).

Os Contraceptivos Hormonais Orais são esteróides utilizados isoladamente ou em associação, e tem como finalidade básica impedir a concepção. É um método usado em larga escala pela população feminina, pois o seu controle de natalidade é muito difundido há décadas (MATTOS et al., 2012). Possuem ainda outros benefícios como a redução no risco de cistos ovarianos, câncer ovariano e endometrial e doença mamária benigna; menor incidência de doença inflamatória pélvica (DIP) e gravidez ectópica (tubária); melhora dos sintomas prémenstruais, da dismenorreia e da endometriose e também diminuição do fluxo no ciclo menstrual (RANIERI et al., 2011).

Alguns fatores estão associados à perda da eficácia do medicamento: além do esquecimento de tomar o comprimido, também o uso concomitante a outros medicamentos 
(MARQUES, et al., 2008). Portanto, seu efeito depende do uso correto, em horário regular e iniciando as cartelas em dias apropriados, o que compete à própria mulher controlar. Estima-se que a taxa de falha de oito gravidezes para 100 usuárias a cada ano; desde que não haja erros no uso, menos de uma gravidez poderá ocorrer para 100 mulheres/ano. $\mathrm{O}$ aumento dessas taxas, bem como o maior aparecimento dos efeitos colaterais, está diretamente relacionado a esse uso incorreto de anticoncepcionais hormonais orais combinados, razão importante para a descontinuidade do uso (AMÉRICO et al., 2013).

O uso concomitantemente da pílula com antibióticos (também chamados de antimicrobianos) pode não fazer efeito; ou seja, a administração de dois ou mais medicamentos, principalmente antibióticos, contribui para diminuição da eficiência dos anticoncepcionais aumentando o risco das interações, as quais podem reduzir o efeito terapêutico ou aumentar a toxicidade do medicamento, levando a problemas graves de saúde e principalmente a concepção (MARTINS et al., 2014). Essas interações estão, sem dúvidas, entre as questões atuais mais complexas e de grande importância para os profissionais da saúde, nesse caso recomenda-se uso da pílula com dosagem de estrógeno mais alto, ou ainda, uso de outros métodos contraceptivos, como camisinha, DIU, tabelinha, etc. (SOUZA et al., 2005).

Em 1993, a Organização Mundial da Saúde (OMS) reconheceu o papel do farmacêutico no sistema de atenção à saúde, em colaboração com outros membros da equipe, a fim de atender às necessidades dos pacientes e assegurar o uso correto dos medicamentos. Esse tipo de ação serve como um modelo de prática profissional desenvolvida no contexto da $\mathrm{AF}$ e, de acordo com a proposta de Consenso Brasileiro de Atenção Farmacêutica, possui por finalidade aumentar a efetividade do tratamento medicamentoso, concomitante à detecção de Problemas Relacionados a Medicamentos (PRMs) (OLIVEIRA, 2005).

\section{Metodologia}

A cidade de Vitoria da Conquista está localizada na região Nordeste do Brasil e situada na região Sudoeste baiano, à $527 \mathrm{Km}$ da capital, Salvador. Ocupada por uma área total de 3216 Km2, com uma população de 306.866 habitantes e com população estimada, em 2016, em 346.069 habitantes, segundo regionalização do IBGE. 
Apresenta coordenadas geográficas como altitude $923 \mathrm{~m}$, Latitude $14^{\circ} 51^{\prime} 58^{\prime} \mathrm{S}$, Longitude $40^{\circ} 50^{\prime} 22^{\prime}$ W, O clima é quente e temperado. A classificação do clima é Cwb segundo a Köppen e Geiger. Em Vitória da Conquista a temperatura média é $20.0^{\circ} \mathrm{C} .712 \mathrm{~mm}$ é o valor da pluviosidade média anual.

Esta pesquisa foi realizada numa drogaria desta cidade. Foram abordadas as temáticas referentes aos benefícios à saúde da população onde buscam melhor esclarecer ao paciente, a respeito da prescrição médica apresentada, no ambiente de uma farmácia.

Estes setores são definidos e utilizados pelo Instituto Brasileiro de Geografia e Estatística (IBGE) fornecendo uma base de dados de indicadores socioeconômicos e de saúde, para fins de controle cadastral. Delimitando-se por idade amostra do estudo foi do sexo feminino com idades entre 18 a 25 e 26 a 46 anos, mulheres com prescrições de medicamentos antibacterianos, aviadas e retidas, que fazem o uso de contraceptivos tanto de uso oral quanto injetável, e as que nesse período fizeram o uso de antimicrobianos. Este mesmo questionário foi realizado na farmácia de Vitoria da Conquista, sendo utilizada como métodos de abordagem a aplicação de formulários junto à população.

O formulário aplicado teve como objetivo a verificação do perfil de utilização de medicamentos e reconhecimento de possíveis interações entre antibióticos e anticoncepcionais. O formulário conteve perguntas objetivas, na qual os entrevistados responderam os seguintes tópicos: Dados pessoais; Em relação à medicação, com que frequência toma e nome do medicamento; Com relação ao ato da prescrição médica: $\mathrm{O}$ médico antes de prescrever fez alguns tipo de pergunta? Ou orientações? dentre outras (cf. ANEXO A).

As fontes de pesquisa serão o Instituto Brasileiro de Geografia e Estatística (IBGE), que fornecerá informações da cidade de Vitoria da Conquista acerca da população local, um levantamento bibliográfico em artigos, revistas, teses, livros e dissertações para compor uma base de dados, aprimorando os conhecimentos referentes à interações medicamentosas, uso de medicamentos anticoncepcionais utilizados juntamente com antibióticos a importância relações médico-paciente e farmacêutico- paciente, como um aspecto chave para a melhoria da qualidade do serviço de saúde, conscientizar os médicos que os pacientes necessitam de orientação clara sobre os riscos da administração concomitante de vários fármacos, evitando assim as interações medicamentosas, 
As informações foram registradas pelo próprio entrevistado (autopreenchimento), onde os mesmos tiveram a oportunidade de esclarecer dúvidas com o entrevistador. Foram orientados quanto aos objetivos do trabalho e ficaram livres para participar, mediante assinatura do Termo de Consentimento Livre e Esclarecido - TCLE, obedecendo aos princípios éticos que constam na resolução 466/12 do Conselho Nacional de Saúde - CNS, que define as diretrizes e normas regulamentadoras de pesquisas envolvendo seres.

A análise dos dados obtidos foi analisada utilizando estatística descritiva e elaborando um banco de dados com o auxílio do software Microsoft e Excel 2010, onde os dados foram tabulados e representado em forma de gráficos.

\section{Resultados e Discussão}

A amostra do estudo na drogaria foi realizada com 396 clientes do sexo feminino, com idade média 26,2 anos (DP \pm 5,9). Mediante os questionários aplicados e os resultados apresentados, observou-se uma variação do perfil das entrevistadas em relação à utilização de medicamentos e suas possíveis interações medicamentosas. No que se refere aos antimicrobianos e anticoncepcionais orais ou injetáveis, mulheres que fizeram o uso regularmente de antibiótico foram 133 (cento e trinta e três), 291(duzentos e noventa e um) faz uso diário de anticoncepcionais oral e 70 (setenta) delas fazem uso de anticoncepcionais injetáveis (cf. GRÁFICO 1).

GRÁFICO 1- Relação à medicação, com que freqüência toma e nome do medicamento.

Frequência no uso de medicamentos

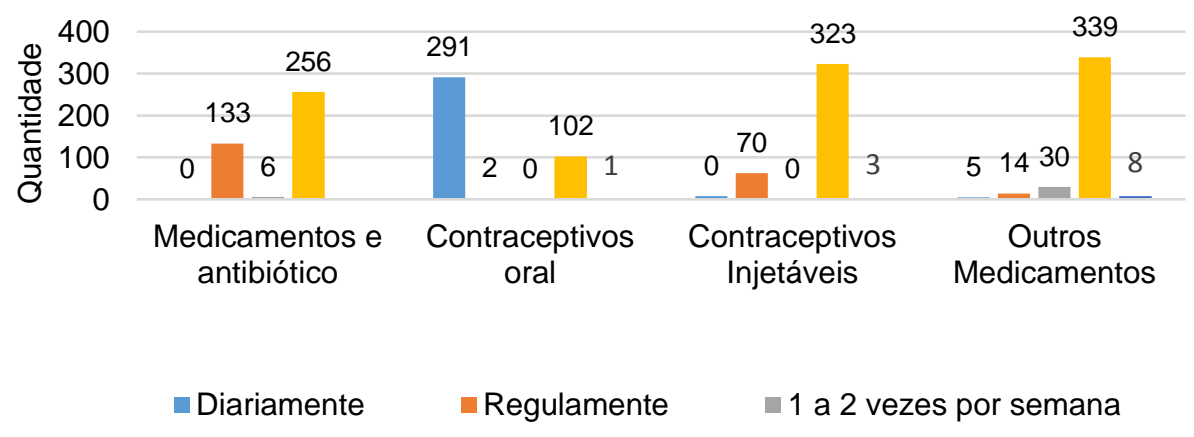

Fonte: Informações do Próprio Pesquisador 
A tabela 1 demonstra em percentual valores referentes à utilização ou não dos medicamentos e sua frequência, em uma faixa etária que varia de 18 a 25 anos e de 26 a 46 anos. Vejamos:

Tabela 1 - Quantidade de Pessoas entrevistadas COM IDAde de 18 a 25 anos e De 26 a 46 anos E SUAS RESPECTIVAS RESPOSTAS FRENTE À UTILIZAÇÃO OU NÃO DE MEDICAMENTOS ANTIBIÓTICOS, CONTRACEPTIVOS ORAIS E CONTRACEPTIVOS INJETÁVEIS.

\begin{tabular}{lccc}
\hline & $\mathbf{1 8 - 2 5}$ anos & $\mathbf{2 6 - 4 6}$ anos & Total \\
\hline Associam & 135 & 152 & 287 \\
\hline Não associam & 56 & 53 & 109 \\
\hline Fonte: Informaços dóprio Pesquisador
\end{tabular}

Fonte: Informações do Próprio Pesquisador

É possível evidenciar que $48 \%$ (quarenta e oito por cento) representa uma faixa etária de 18 a 25 anos e 52\% (cinquenta e dois por cento) representa uma faixa etária de 26 a 46 anos. A partir das respostas relatadas e das referidas faixa etária, pode-se dizer que, 47,0\% (quarenta e sete por cento) das mulheres entrevistadas entre $18-25$ anos e 53,0\% (cinquenta e três por cento) entre 26-46 anos relataram fazer uso de antibiótico em associação com contraceptivo, evidenciando uma possível interação medicamentosa.

Com relação às mulheres que relataram fazer uso ou de antimicrobiano ou de anticoncepcional não os associando, o percentual referente para tal informação foi de $51 \%$ (cinquenta e um por cento) correspondente à faixa etária entre 18-25 anos e 49\% (quarenta e nove por cento) correspondente à faixa etária de 26-46 anos. Observou que os anticoncepcionais orais foi o método contraceptivo mais utilizado quando comparado com outros métodos anticoncepcionais.

Os contraceptivos orais mais modernos tem sua concentração de ativos diminuída a fim de minimizar seus efeitos adversos. Sob circunstancias normais, estas concentrações são bem efetivas. Porém, na presença de antimicrobianos, os níveis hormonais, podem vir a cair ainda mais, comprometendo a eficácia dos contraceptivos. A redução da eficácia contraceptiva ocorre por alteração da flora intestinal.

Quando os anticoncepcionais orais são ingeridos, o estrógeno e a progesterona são absorvidos no trato gastrintestinal para a corrente sanguínea, sendo conduzidos até o fígado, 
onde são metabolizados. Os níveis circulantes de anticoncepcionais orais, podem ser reduzidos com a utilização de antibióticos de amplo espectro, levando a falhas em mulheres que fazem uso desse método contraceptivo (ZHANEL et al. 1999).

Como vimos na Tabela 1, das 396 mulheres entrevistadas, identificou-se que 287 delas fazem uso de antibiótico associado a algum tipo de anticoncepcional, ocorrendo assim alguma interação. "Segundo dados da Organização Mundial da Saúde, as infecções causam 25\% das mortes em todo o mundo e 45\% nos países subdesenvolvidos." (NICOLINI et al.,2008). "O uso descontrolados dos antibióticos sem uma cuidadosa avaliação das suas indicações apropriadas pode levar ao crescimento de cepas resistentes, ou seja, acarretar numa mutação seletiva.”(NICOLINI et al., 2008)

A análise das prescrições permite a identificação de erros e problemas e a necessidade de implantação de medidas corretivas e educativas e avaliar o impacto da adoção dessas medidas. As deficiências nas informações nas prescrições são responsáveis por grande parte dos erros de medicação (BENJAMIN, 2003; ABRANTES et al, 2007).

Diante deste perfil, houve a necessidade de realizar algumas perguntas, com relação às orientações prestadas pelo médico no ato da prescrição. Estando correlacionas no gráfico 2 , no ato da prescrição o médico orientou o paciente se ele fazia o uso de alguma medicação diária, 254 (duzentos e cinquenta e quarto) responderam que foram orientados e 142 (cento e quarenta e dois) não obtiveram orientação médica (cf. GRÁFICO 2).

Dos pacientes que foram orientados pelo médico sobre serem alérgicos a algum tipo de medicamento, 270 (duzentos e setenta e dois) disseram que foram orientados e 125 (cento vinte e cinco) não foram orientados. Quanto as possíveis interações existentes nas prescrições, 303 (trezentos e três) não houveram orientação e 91 (noventa e um) tiveram orientação. Sobre administração correta dos medicamentos prescritos 252 (duzentos e cinquenta e dois) tiveram 142 (cento quarenta e dois) não tiveram. Com relação os pacientes que fazem uso de contraceptivo injetável, 41 (quarenta e um) não obtiveram orientação sobre a restrição de uso de antimicrobianos e 30 (trinta) foram orientados. Os 325 (trezentos vinte e cinto) que consta são os entrevistados que não faz uso dos contraceptivos injetáveis. 
GRÁFICO 2- Com relação ao ato da prescrição médica: O médico antes de prescrever fez alguns tipo de pergunta? Ou orientações?

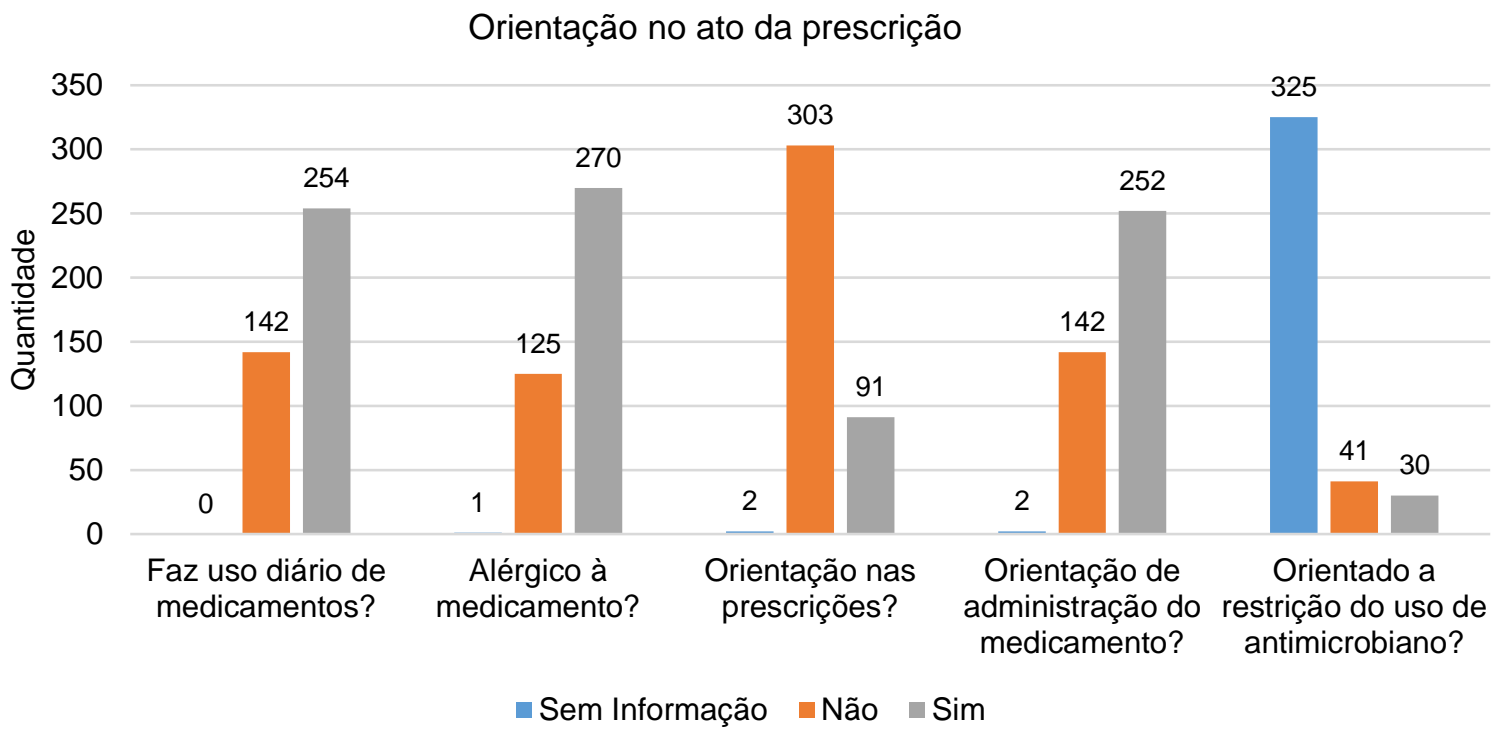

Fonte: Informações do Próprio Pesquisador

De acordo com a Portaria GM/MS 3.916/98 e a Portaria SVS/MS 344/98, a prescrição é o ato de definir a medicação a ser consumida pelo paciente com a dosagem respectiva, duração do tratamento e orientação do uso; no geral esse ato é expresso mediante a elaboração da receita (prescrição medicamentosa), quer seja de formulação magistral ou de produto industrializado, por um profissional legalmente habilitado (MASTROIANNI, 2009).

Prescrições incompletas impossibilitam a eficiência da dispensação dos medicamentos que coloca em risco a qualidade da Assistência Farmacêutica ao paciente (SILVÉRIO; LEITE, 2010). Winterstein e colaboradores (2004) mostram que $72 \%$ dos erros de medicação foram iniciadas durante a elaboração da prescrição, seguidos pela administração (15\%), dispensação (7\%) e transcrição (6\%) (ALVES; SANTIAGO; SANTOS, 2013). “A prescrição tem como um papel primordial no tratamento medicamentoso por ser um instrumento que contribui para posologia correta dos medicamentos". A relações médico-paciente e farmacêutico-paciente, tem se como um aspecto chave para a melhoria da qualidade do serviço de saúde, no qual a preconiza a assistência, a humanização do atendimento e o direito das informação básicas para o mesmo (MASTROIANNI, 2009). 
O gráfico abaixo mostra a quantidade de pessoas que relatou obter ou não orientações no ato da prescrição, frente à existência ou não de interação medicamentosa. Vejamos

GRÁFICO 3 - PERGUNTA REALIZADA PELO MÉDICO PARA O PACIENTE NO ATO DA PRESCRIÇão, QUANTO AO USO DIÁRIO DE MEDICAMENTOS PELO PACIENTE.

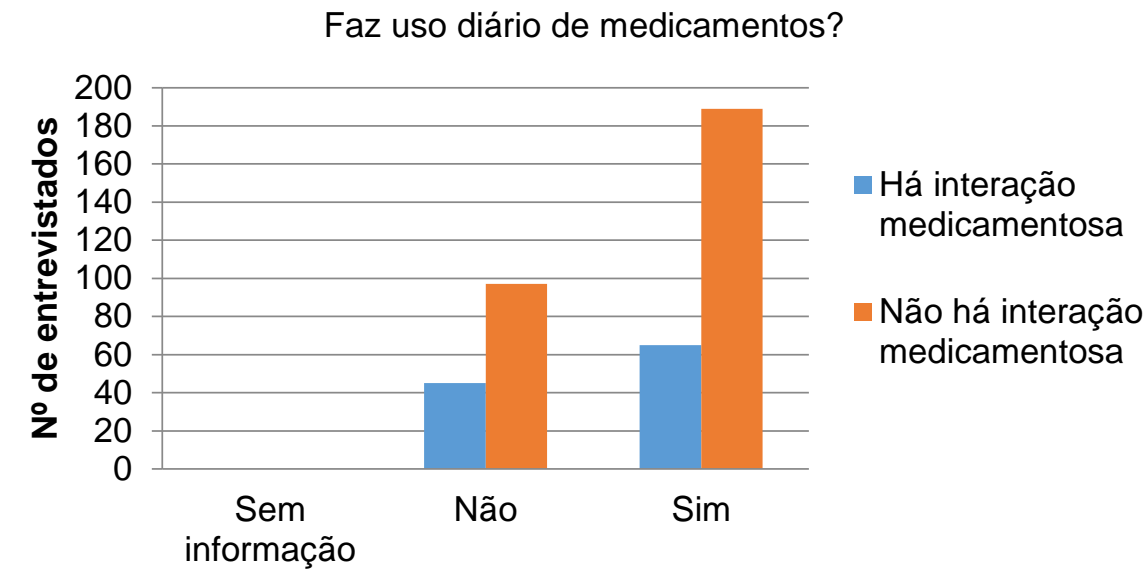

Respostas adquiridas

Fonte: Informações do Próprio Pesquisador

Nota-se no gráfico 3 que, o médico não fez essa pergunta para 142 (cento e quarenta e duas) mulheres, onde 45 (quarenta e cinco) faz uso de dois medicamentos (antibiótico + contraceptivo) havendo interação e, 97 (noventa e sete) mulheres faz uso somente de antimicrobiano ou somente de anticoncepcional, não havendo interação medicamentosa.

Já as mulheres que responderam que o médico na sua orientação perguntou corresponderam um total de 254 (duzentos e cinqüenta e quatro), representando 65 (sessenta e cinco) mulheres que faz uso de dois medicamentos (antibiótico + contraceptivo) havendo interação medicamentosa e, 189 (cento e oitenta e nove) mulheres faz uso separadamente de ambos, não havendo interação medicamentosa. 


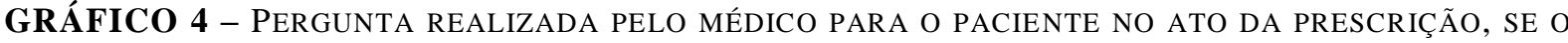
MESMO É ALÉRGICO A ALGUM TIPO DE MEDICAMENTO.

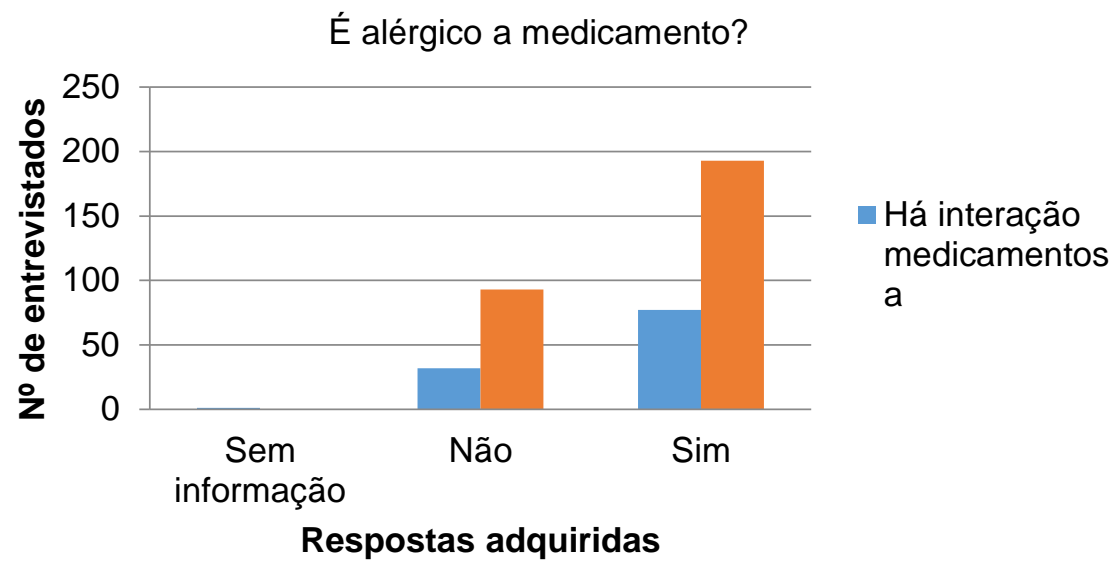

Fonte: Informações do Próprio Pesquisador

Para a referida orientação sobre processos alérgicos relacionados a medicamento, observou-se que 125 (cento e vinte e cinco) mulheres responderam não ter recebido orientação médico quanto a ser alérgica ou não a medicamentos e, que deste total, 32 (trinta e duas) ocorre interação e 93 (noventa e três) não possui interação medicamentosa. Para aqueles que responderam sim, que o médico fez a pergunta, 77 (setenta e sete) mulheres há interação medicamentosa e 193 (cento e noventa e três) não existe interação, representando um total de 270(duzentos e setenta) mulheres.

GRÁFICO 5 - PERgunta REALIZAda PELO MÉDiCo PARA O PACIENTE NO ATO DA PRESCRIÇÃo SOBRE POSSÍVEIS INTERAÇÕES MEDICAMENTOSAS.

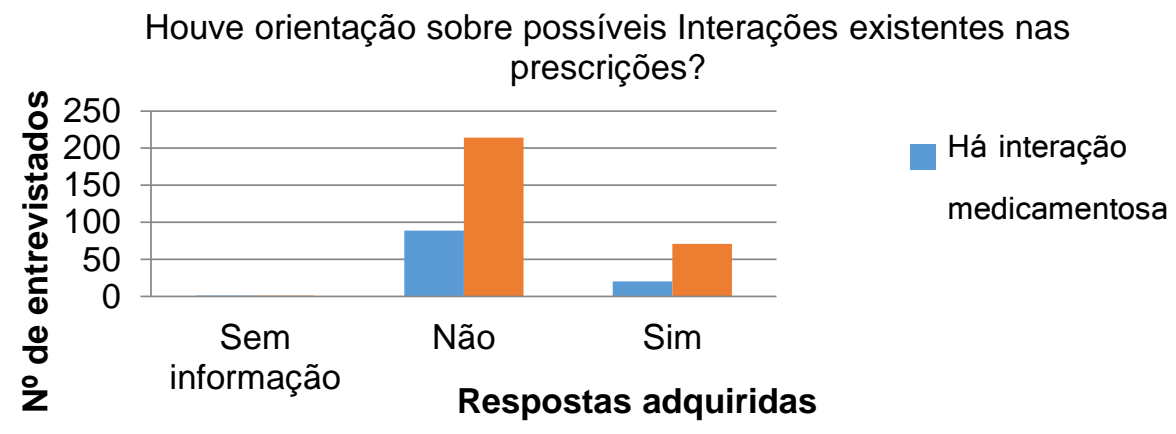

Fonte: Informações do Próprio Pesquisador 
A importância dada ao médico no que se referem às informações fornecidas ao paciente sobre interações medicamentosas, pode ser observada no gráfico 5, quando um total de 303 (trezentos e três) mulheres responderam que esta pergunta não foi feita pelo médico, onde 89 (oitenta e nove) mulheres possuía interação medicamentosa com os referidos medicamentos em uso e, que 214 (duzentos e quatorze) mulheres faziam uso de algum tipo de medicamento (antibiótico ou anticoncepcional), não havendo interação medicamentosa. Das mulheres que relataram ter sido orientada a respeito de possíveis interações existentes na prescrição, 20 (vinte) fazia uso de antibiótico com anticoncepcional havendo interação e, 71 (setenta e uma) mulheres fazia uso de anticoncepcional ou de antibiótico, não havendo interação medicamentosa.

GRÁFICO 6 - PERgunta REALIZADA PELO MÉdico PARA O PACIENTE NO ATO DA PRESCRIÇão SOBRE A FORMA DE ADMINISTRAR OS MEDICAMENTOS.

Foi orientado sobre a forma de administração dos medicamentos?

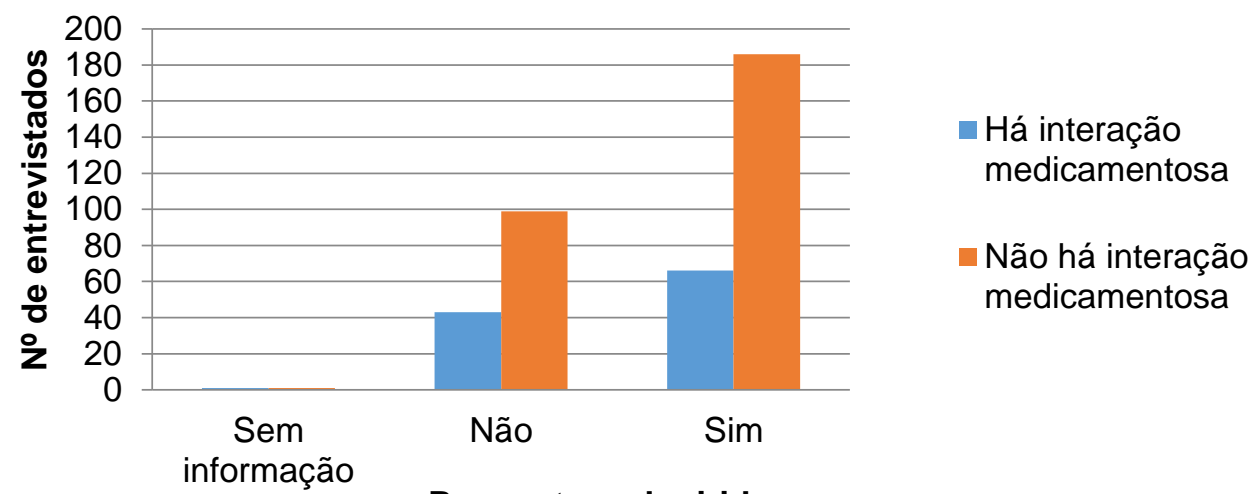

Respostas adquiridas

Fonte: Informações do Próprio Pesquisador

Em relação à explicação por parte do médico em orientar sobre a forma correta de administrar os medicamentos em estudo. Viu-se que, 142 (centro e quarenta e duas) mulheres relataram não ter recebido este tipo de orientação o que equivale a 43 (quarenta e três) mulheres possuindo algum tipo de interação e 99 (noventa e nove) não havendo qualquer tipo de interação. 


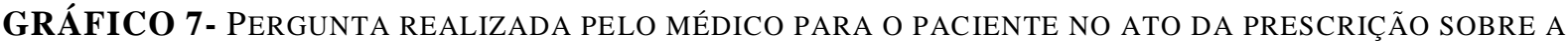
UTILIZAÇÃO DE CONTRACEPTIVOS INJETÁVEIS E A RESTRIÇÃO DO USO DE ANTIMICROBIANO.

No uso de contraceptivo injetável foi orientado a restrição do uso de antimicrobiano?
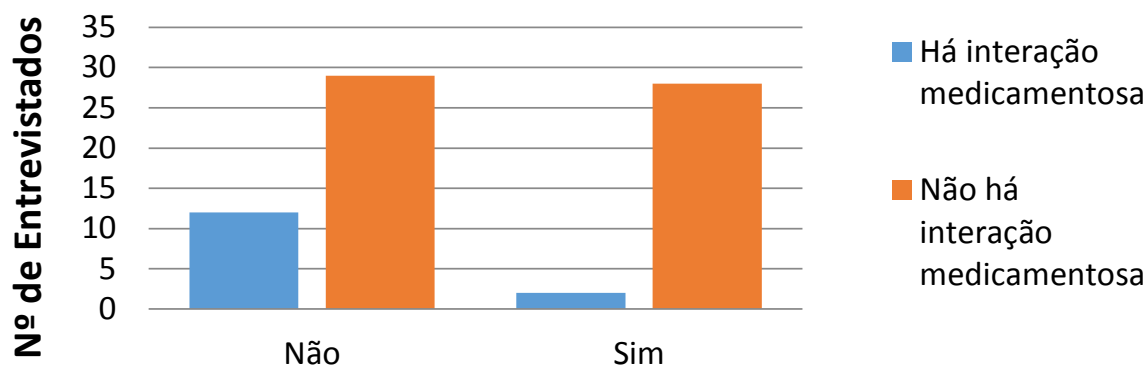

Resposta Adquirida

Fonte: Informações do Próprio Pesquisador

Sobre o uso de contraceptivos injetáveis e a restrição do uso de antimicrobianos, relatada no ato da prescrição, é possível notar que, 41 (quarenta e uma) mulheres responderam não ter obtido está orientação na consulta médica (12 possuindo interação e 29 não possuindo interação). Já aquelas que relataram ter sido orientada pelo médico, apenas 2 (dois) relatos havia interação medicamentosa e 28 (vinte e oito) não havia interação medicamentosa.

Analisado se no ato da prescrição o médico orientou a paciente, sobre as possíveis interações existentes. Das mulheres, 76,5\% responderam não foi realizada essa orientação e $23 \%$ que tiveram essa orientação. Na orientação do médico no ato da administração do medicamento $15,8 \%$ disseram que não foram orientadas e 63,6\% afirmaram a orientação. Em pacientes que fazem o uso de contraceptivo injetável, quando é feita a administração do mesmo, é orientada a restrição do uso de antimicrobiano, 10,4 responderam que não ocorreu essa orientação e 7,6\% tiveram orientações sobre a restrição do uso de antibiótico, $82 \%$ das mulheres não souberam informar, como mostra a gráfico 5. A falta de orientação médica sobre possíveis interações dos medicamentos pode acarretar em danos gravíssimos relacionado a saúde do paciente.

Existe uma grande quantidade de fármacos capazes de provocar a diminuição da eficácia contraceptiva, fármacos como a amoxicilina, eritromicina, penicilina, rifampcina e tetraciclinas, onde provocam alterações na absorção intestinal dos anticoncepcionais orais. 
Santos et al (2006) observou que a rifampcina é um dos medicamentos mais frequentemente implicados a gravidez acidental em usuários de contraceptivo oral.

Com relação a orientação do médico com pacientes que fazem o uso de contraceptivos injetáveis, Coutinho (1996) considera que uso mensal ou trimestral de hormônio em forma de injeção este anticoncepcional, comercializado com o nome de Depo Provera e Farlutal 500 AD, como ideal para suprimir a menstruação. Os progestógenos injetáveis, além de anovulatórios, aumentam a viscosidade do muco cervical, tornam o endométrio menos propício à implantação do ovo e alteram a motilidade tubária. É método requer supervisão mínima e tem efeito prolongado, sendo recomendável para pessoas com deficiência mental. Entretanto, para a sua escolha, deve ser avaliada a ausência de contra-indicações, como câncer, cardiopatias, doenças do fígado. Devem ser também levadas em conta as desvantagens do método, principalmente a irregularidade menstrual, aumento de peso e certa demora para retornar a fertilidade.

Em uma pesquisa feita em Fortaleza por Arrais et al. (2007) observou-se que a maioria dos pacientes $(92,5 \%)$ foram orientados pelo médico a tomar o medicamento prescrito $(92,5 \%)$ e a cumprir adequadamente o tratamento $(70,6 \%)$, menosprezando, na maioria das vezes, os cuidados com as possíveis reações adversas e interações medicamentosas.

Segundo o Conselho Federal de Medicina (CFM) (2009), é necessário a transparência do médico na prescrição, esclarecendo e orientando o paciente de possíveis reações adversas. A falta de conhecimento sobre os medicamentos coloca em risco a saúde do paciente e a credibilidade do profissional.

Os pacientes necessitam de orientação clara sobre os riscos da administração concomitante de vários fármacos. Também outros cuidados devem ser alertados, principalmente para os pacientes que utilizam anticoagulantes, hipoglicemiantes orais, digitálicos, psicotrópicos, inibidores da monoaminoxidase e fármacos citotóxicos (Arrais et al. 2007).

\section{Conclusões}

É possível concluir sobre há falta de conhecimento das entrevistadas sobre as possíveis interações medicamentosas existentes quando em uso associado de antimicrobiano e 
contraceptivo oral ou injetável. Nota-se, também, o desinteresse por parte do prescritor em orientá-las, resultando em diminuição da eficácia por parte dos anticoncepcionais.

A correta escolha do antibiótico e a orientação devida ao paciente e de grande responsabilidade dos profissionais da saúde. Cabe ao farmacêutico, por ser um profissional capacitado, avaliar as prescrições, sugerir o uso racional de medicamentos e praticar a atenção farmacêutica, proporcionando informação e orientação imparcial sobre a utilização dos mesmos. Este profissional deve orientar a população não só quanto aos medicamentos prescritos, mas também aos de venda livre. Com isso, tanto ele quanto os demais profissionais de saúde devem ser treinados para dar a devida informação sobre as patologias e tratamentos para diminuir a utilização inadequada de antimicrobianos e assim melhorar a qualidade de vida dos pacientes.

\section{Referências}

ALVES, T. N. P.; SANTIAGO, T. C.; SANTOS, L. Z. Análise das prescrições médicas em Unidades de Atenção Primária à Saúde do município de Juiz de Fora-MG. Convibra, n. February 2012, p. 17, 2013.

BEATRIZ, A. N. A.; SOUZA, G. D. E. Revista eletrônica estácio saúde. Revista Eletronica Estácio Saúde, v. 3, n. 2, p. 1-10, 2014.

MARTINS, N. B. et al. Análise De Prescrição Médica De Antibióticos De Uma Farmácia Comercial Do Município De Imperatriz-Ma. Revista Científica do ITPAC, v. 7, n. 4, p. 1-9, 2014.

MASTROIANNI, P. D. C. Analise dos aspectos legais das prescriçoes de medicamentos. Revista de Ciencias Farmaceuticas Basica e Aplicada, v. 30, n. 2, p. 173-176, 2009.

MEIRELLES, L.; ROCHA, M. Interações Medicamentosas Dos Anticoncepcionais Com Outros Fármacos. Centro de Pós-Graduação Oswaldo Cruz, 2013.

NICOLINI, P. et al. Fatores relacionados à prescrição médica de antibióticos em farmácia pública da região Oeste da cidade de São Paulo. Ciência \& Saúde Coletiva, v. 13, n. April 2008, p. 689-696, 2008.

ALVES, T. N. P.; SANTIAGO, T. C.; SANTOS, L. Z. Análise das prescrições médicas em Unidades de Atenção Primária à Saúde do município de Juiz de Fora-MG. Convibra, n. 
February 2012, p. 17, 2013.

BEATRIZ, A. N. A.; SOUZA, G. D. E. Revista eletrônica estácio saúde. Revista Eletronica Estácio Saúde, v. 3, n. 2, p. 1-10, 2014.

MARTINS, N. B. et al. Análise De Prescrição Médica De Antibióticos De Uma Farmácia Comercial Do Município De Imperatriz-Ma. Revista Científica do ITPAC, v. 7, n. 4, p. 1-9, 2014.

MASTROIANNI, P. D. C. Analise dos aspectos legais das prescriçoes de medicamentos. Revista de Ciencias Farmaceuticas Basica e Aplicada, v. 30, n. 2, p. 173-176, 2009.

MEIRELLES, L.; ROCHA, M. Interações Medicamentosas Dos Anticoncepcionais Com Outros Fármacos. Centro de Pós-Graduação Oswaldo Cruz, 2013.

NICOLINI, P. et al. Fatores relacionados à prescrição médica de antibióticos em farmácia pública da região Oeste da cidade de São Paulo. Ciência \& Saúde Coletiva, v. 13, n. April 2008, p. 689-696, 2008.

ZHANEL, George G.; SIEMENS, Shannon; SLAYTER, Kathryn; MANDELL, Lionell. Antibiotic and oral contraceptive drug interactions: Is there a need for concern? Can J Infect Dis. Vol 10 - nº 6. Novembro/Dezembro 1999.

Como citar este artigo (Formato ABNT):

MENDONÇA, Deborah S.B.; RODRIGUES, Rafael L.A. Interações Medicamentosas entre Antibióticos e Anticoncepcionais, presentes em Prescrições Médicas. Id on Line Revista Multidisciplinar e de Psicologia, Abril de 2017, vol.11, n.35, p.67-83. ISSN: 1981-1179.

Recebido: 15.05 .2017

Aceito: .17.05.2017

Anexo

Questionário da Pesquisa

TEMA: INTERAÇÕES MEDICAMENTOSAS ENTRE ANTIBIÓTICOS E ANTICONCEPCIONAIS, ENCONTRADAS NAS PRESCRIÇÕES MÉDICAS APRESENTADAS NUMA DROGARIA DE VITORIA DA CONQUISTA

PESQUISADORA: DÉBORAH SORAIA BRANDÃO MENDONÇA 
Id on Line Revista Multidisciplinar e de Psicoloqia

Id on Line Multidisciplinary and Psycology Journal

\section{Introdução:}

Estamos realizando uma pesquisa sobre INTERAÇÕES MEDICAMENTOSAS ENTRE ANTIBIÓTICOS E ANTICONCEPCIONAIS, ENCONTRADAS NAS PRESCRIÇÕES MÉDICAS e gostaríamos de contar com sua colaboração. Asseguramos a confidencialidade das informações, que serão tratadas no conjunto e, para fins acadêmicos. Você pode retirar-se da pesquisa no momento que achar conveniente.

Aceita responder o questionário? $\quad \operatorname{SIM}($ ) NÃO ( ) Data:

Nome (Completo):

Gênero: M ( ) F ( )

Idade:

Data de Nascimento:

Escolaridade: ( ) Nenhuma ( ) Ensino fundamental incompleto ( ) Ensino fundamental

( ) Ensino Médio incompleto ( ) Ensino Médio ( ) Ensino Superior incompleto ( ) Ensino Superior

Profissão:

Trabalha atualmente: ( ) Sim ( ) Não

idade em que reside: ( ) Vitória da Conquista ( ) Outros Se outros, especifique:

Naturalidade: ( ) Vitória da Conquista ( ) Outros Se outros, especifique:

\section{Endereço (opcional):}

Bairro (opcional):

Data do último exame médico:

Em relação à medicação, com que frequência toma e nome do medicamento :

\begin{tabular}{|c|c|c|c|c|c|}
\hline & Nunca & $\begin{array}{l}1 \text { a } 2 \text { vezes por } \\
\text { semana }\end{array}$ & Regulamente & Diariamente & Nome \\
\hline $\begin{array}{l}\text { Medicamentos } \\
\text { antibióticos }\end{array}$ & $(\quad)$ & $($ ) & $($ ) & $($ ) & \\
\hline $\begin{array}{l}\text { Contraceptivos } \\
\text { oral }\end{array}$ & ( ) & ( ) & ( ) & ( ) & \\
\hline $\begin{array}{l}\text { Contraceptivos } \\
\text { Injetáveis }\end{array}$ & $(\quad)$ & $($ ) & $($ ) & $($ ) & \\
\hline $\begin{array}{l}\text { Outros } \\
\text { Medicamentos }\end{array}$ & $(\quad)$ & ( ) & ( ) & $($ ) & \\
\hline $\begin{array}{l}\mathrm{Se} \text { usa outr } \\
\text { medicamentos, } \\
\text { especifique: }\end{array}$ & & & & & \\
\hline
\end{tabular}


Com relação ao ato da prescrição médica: $O$ médico antes de prescrever fez alguns tipo de pergunta? Ou orientações?

\begin{tabular}{|l|c|c|}
\cline { 2 - 3 } \multicolumn{1}{l|}{} & SIM & NÃO \\
\hline $\begin{array}{l}\text { Faz uso de alguns medicamento } \\
\text { diariamente? }\end{array}$ & $($ ) & $($ ) \\
\hline $\begin{array}{l}\text { É alérgico algum tipo de } \\
\text { medicamento? }\end{array}$ & $(\quad)$ & $(\quad$ ) \\
\hline $\begin{array}{l}\text { Foi orientado das possíveis } \\
\text { interações existentes nas } \\
\text { prescrições? }\end{array}$ & $(\quad)$ & $(\quad)$ \\
\hline $\begin{array}{l}\text { Foi orientado a forma correta da } \\
\text { administração do medicamento? }\end{array}$ & $(\quad)$ & $(\quad$ ) \\
\hline $\begin{array}{l}\text { Em caso de pacientes que faz uso } \\
\text { de contraceptivos injetável, } \\
\text { quando é feita a administração do } \\
\text { mesmo, é orientado a restrição do } \\
\text { uso de antimicrobiano? }\end{array}$ & $(\quad)$ & \\
\hline
\end{tabular}

